TITLE:

$\beta$-Blocker therapy and cardiovascular outcomes in patients who have undergone percutaneous coronary intervention after ST-elevation myocardial infarction(Dissertation_全文 )

$\operatorname{AUTHOR}(\mathrm{S}):$

\title{
Bao, Bingyuan
}

\section{CITATION:}

Bao, Bingyuan. B-Blocker therapy and cardiovascular outcomes in patients who have undergone percutaneous coronary intervention after ST-elevation myocardial infarction. 京都大学, 2014, 博士(医学)

ISSUE DATE:

2014-03-24

URL:

https://doi.org/10.14989/doctor.k18162

RIGHT: 
Beta-blocker Therapy and Cardiovascular Outcomes in Patients Who Have Undergone Percutaneous Coronary Intervention After ST-elevation Myocardial Infarction

Short title: Beta-blockers in Myocardial Infarction, Word count for text: 2,589 words

Bingyuan Bao, M.D.*, Neiko Ozasa, M.D.*, Takeshi Morimoto, M.D., M.P.H.†, Yutaka Furukawa, M.D.†, Yoshihisa

Nakagawa, M.D.§, Kazushige Kadota, M.D.||, Masashi Iwabuchi, M.D.II, Satoshi Shizuta, M.D.*, Hiroki Shiomi, M.D.*,

Tomohisa Tada, M.D.*, Junichi Tazaki, M.D.*, Yoshihiro Kato, M.D.*, Mamoru Hayano, M.D.*, Masahiro Natsuaki,

M.D.*, Hisayoshi Fujiwara, M.D.\#, Kazuaki Mitsudo, M.D.\|, Masakiyo Nobuyoshi, M.D. II, Toru Kita, M.D.ł, Takeshi

Kimura, M.D.*, on behalf of the CREDO-Kyoto AMI registry investigators.

*Department of Cardiovascular Medicine, Graduate School of Medicine, Kyoto University, †Center for General Internal

Medicine and Emergency Care, Kinki University School of Medicine, $\$$ Department of Cardiovascular Medicine, Kobe

City Medical Center General Hospital, §Division of Cardiology, Tenri Hospital, „|Division of Cardiology, Kurashiki

Central Hospital, q[Division of Cardiology, Kokura Memorial Hospital, \#Division of Cardiology, Hyogo Prefectural

Amagasaki Hospital.

Corresponding author: Neiko Ozasa, Department of Cardiovascular Medicine, Kyoto University Graduate School of

Medicine, 54 Shogoin, Kawahara-cho, Sakyo-ku, Kyoto, 606-8507, Japan. Fax number: +81-75-751-3299, Tel.:

+81-75-751-4255, E-mail address: nei126@kuhp.kyoto-u.ac.jp. 


\section{Abstract}

The effect of $\beta$-blockers in ST-elevation myocardial infarction (STEMI) patients who have undergone primary

percutaneous coronary intervention (PCI) has not been adequately evaluated. Using a large multi-center registry in Japan, we identified 3,692 patients who underwent PCI within 24 hours from onset of STEMI and were discharged alive from 2005 to 2007. Three-year cardiovascular outcomes were compared between the 2 groups of patients with $(\mathrm{N}=1,614)$ or without $(\mathrm{N}=2,078) \beta$-blocker prescription at discharge. Compared with patients in the no- $\beta$ group, patients in the $\beta$ group were younger, more frequently male, more often had hypertension and atrial fibrillation but less often had chronic obstructive pulmonary disease than in the no- $\beta$ group. Statins and angiotensin-converting enzyme inhibitors /angiotensin receptor blockers were more frequently prescribed in the $\beta$ group. Crude incidence of cardiac death and/or recurrent myocardial infarction (cardiac death/MI) tended to be higher in the $\beta$ group (7.6\% vs. $6.2 \%, \log$-rank p $=0.1)$. After adjusting for potential confounders, $\beta$-blockers were associated with significantly higher risk for cardiac death/MI (hazard ratio $1.43,95 \%$ confidence interval: $1.06-1.94, \mathrm{p}=0.01$ ). Beta-blocker prescription at discharge was not associated with better cardiovascular outcomes in patients who underwent PCI after STEMI. Large-scale randomized controlled trials are needed to evaluate the role of $\beta$-blocker therapy in these patients.

Key Words: Beta-blocker, myocardial infarction, percutaneous coronary intervention, prognosis 


\section{Introduction}

The current clinical guidelines for treatment of ST-segment elevation acute myocardial infarction (STEMI) recommend administration of oral $\beta$-blockers indefinitely to patients who have no contraindications. ${ }^{1,2}$ The guidelines were established on the basis of results from studies conducted in the pre-fibrinolytic era or from studies including a relatively small proportion of patients with early revascularization by thrombolytic therapy or percutaneous coronary intervention (PCI). ${ }^{3,4}$ However, conclusions from observational studies in patients treated with PCI after STEMI were discordant regarding the efficacy of oral $\beta$-blocker therapy. ${ }^{5,6}$ In the Primary Angioplasty in Acute Myocardial Infarction (PAMI) study, it was reported that $\beta$-blockers after PCI were associated with lower 6-month mortality in patients with acute myocardial infarction (AMI). ${ }^{5}$ In contrast, in the j-Cypher study, $\beta$-blockers were not associated with 3 -year mortality in patients who underwent PCI after STEMI and survived the index hospitalization. ${ }^{6}$ However, the sample sizes were relatively small and neither the types nor the doses of $\beta$-blockers were known in the previous studies. Therefore, the present study was designed to examine whether prescription of $\beta$-blockers at discharge was independently associated with improved cardiovascular outcomes in patients who underwent PCI after STEMI using a recent large registry in Japan.

\section{Methods}

The Coronary REvascularization Demonstrating Outcome Study in Kyoto (CREDO-Kyoto) AMI registry is a physician-initiated non-company sponsored multi-center registry that enrolled consecutive AMI patients undergoing coronary revascularization within 7 days of the symptom onset between January 2005 and December 2007 across 26 tertiary hospitals in Japan (Supplemental Appendix A). Among 5,429 patients enrolled in the registry, 4,444 patients 
were diagnosed as STEMI. Excluding 494 patients who underwent PCI beyond 24 hours and 258 patients who died during the index hospitalization, the current study population consisted of 3,692 patients who underwent PCI within 24 hours from onset of STEMI and survived the index hospitalization (Figure 1). Demographics, clinical factors, angiographic data, and discharge medications were collected from hospital charts or hospital databases according to pre-specified definitions by experienced clinical research coordinators (Supplemental Appendix B). Follow-up data were obtained from hospital charts or by contacting patients or referring physicians through 3 years. The relevant review boards or ethics committees in all 26 participating centers approved the study protocol.

\section{Definitions}

Prior myocardial infarction (MI), heart failure (HF), hypertension, current smoking, atrial fibrillation, chronic obstructive lung disease (COPD), liver cirrhosis, and malignancy were regarded as present when these diagnoses were recorded in the hospital charts. Prior stroke was defined as infarction or intracranial bleeding with neurological symptoms lasting $>24$ hours. Peripheral vascular disease was regarded to be present when carotid, aortic, or other peripheral vascular diseases were being treated or scheduled for surgical or endovascular interventions. Left ventricular ejection fraction (LVEF) was measured either by contrast left ventriculography or by echocardiography within 3 months after PCI and low LVEF was defined as LVEF $\leq 40 \%$.

During the follow-up, death was regarded as cardiac in origin unless obvious non-cardiac causes could be identified.

MI was defined according to the definition in the Arterial Revascularization Therapy Study. ${ }^{7}$ Events such as cardiac death and MI were adjudicated by a clinical event committee. Hospitalization for HF was defined as hospitalization due to worsening HF requiring intravenous drug therapy. The primary outcome measure for the current analyses was a 
composite endpoint of cardiac death and recurrent MI (cardiac death/MI). The secondary outcome measures assessed included all-cause death, cardiac death, recurrent MI, and hospitalization for HF.

\section{Statistical methods}

Cumulative incidences of clinical event rates were estimated by the Kaplan-Meier method and differences were assessed with the log-rank test. We used multivariable Cox proportional-hazards model stratified by centers to estimate the hazard ratio (HR) of $\beta$-blocker therapy at discharge for primary and secondary outcome measures by incorporating $\beta$-blocker therapy together with clinically relevant risk-adjusting variables. Adjusted HR and their 95\% confidence interval (CI) were calculated. We computed adjusted cumulative incidence curves of $\beta$ group and no- $\beta$ group using the multivariable Cox proportional-hazards model in conjunction with methods described by Ghali et al. ${ }^{8,9}$ The associations between $\beta$-blocker therapy at discharge and cardiovascular outcomes in the subgroup of patients with preserved and low LVEF were analyzed in the same way. We also performed subgroup analyses of different types and doses of $\beta$-blockers among patients in the $\beta$ group.

Because clinical factors related to treatment selection may be expected to confound the rate of cardiovascular outcomes, we performed a propensity score-matched analysis between the $\beta$ and no- $\beta$ groups as a sensitivity analysis.

Logistic regression was used to calculate the propensity score of prescription of $\beta$-blockers using clinically relevant variables and center. Patients in the $\beta$ group were randomly matched to patients in the no- $\beta$ group using a greedy matching strategy. ${ }^{10}$ Survival analysis comparing the cases and controls was conducted using the Kaplan-Meier method, and statistical comparisons were drawn using the log-rank test.

All analyses were conducted by physicians (B.B. and N.O.) and a statistician (T.M.) using JMP 8 and SAS 9.2 (SAS 
Institute Inc., Cary, NC), and all the reported p values were two-sided. A p value $<0.05$ was regarded as statistically significant.

\section{Results}

Among the total of 3,692 study patients, oral $\beta$-blockers were prescribed in 1,614 patients ( $\beta$ group, $43.7 \%$ ) at hospital discharge, while 2,078 patients were not (no- $\beta$ group, 56.3\%) (Figure 1). There were significant differences in baseline characteristics between the $\beta$ and no- $\beta$ groups (Table 1). Patients in the $\beta$ group were younger, more frequently male, and more often had hypertension, high body weight, high body mass index (BMI), anterior MI, atrial fibrillation, and target of proximal left anterior descending artery. COPD were less prevalent in the $\beta$ group. Statins, angiotensin-converting enzyme inhibitors (ACE-I) /angiotensin receptor blockers, and warfarin were more frequently prescribed in the $\beta$ group (Table 1).

\section{Clinical outcomes}

Median follow-up duration was 955 (IQR: 693-1,248) days. Clinical follow-up were completed in $93.6 \%$ at 1 year, and $87.2 \%$ at 2 years. Three-year incidence of cardiac death/MI was $6.6 \%$ for the entire study population. Crude 3-year incidence of cardiac death/MI was not significantly different between patients in the $\beta$ group and those in the no- $\beta$ group ( $7.6 \%$ vs. $6.2 \%, \log$-rank $\mathrm{p}=0.11$, Table 2 and Figure $2 \mathrm{~A})$. However, after adjusting for 39 potential confounders listed in Table 1, the risk for cardiac death/MI was significantly higher in the $\beta$ group (adjusted HR 1.43, 95\% CI: 1.06-1.94, $\mathrm{p}$ $=0.01$, Supplemental Table 1 and Figure 2A). The risk for hospitalization for HF was also significantly higher in the $\beta$ group, however, the risk for all-cause death was not different between the groups (Table 2).

\section{Subgroup analyses}


In 2,944 patients with LVEF data, 2,494 patients (84.7\%) had preserved LVEF at baseline. The differences in baseline characteristics between the $\beta$ and no- $\beta$ groups in the preserved- and low- LVEF subgroups were similar to the differences in the entire study population (Supplemental Tables 2 and 3). After adjusting for confounding variables, the incidence of cardiac death/MI was higher in the $\beta$ group both in the preserved-LVEF subgroup (adjusted HR 1.27, 95\% CI: $0.87-1.86, p=0.21$ ) and in the low-LVEF subgroup (adjusted HR 1.75, 95\% CI: 0.69-4.47, $\mathrm{p}=0.24$ ), although the differences were not statistically significant (Table 2, Figures $2 \mathrm{~B}$ and 2C).

\section{Types and doses of $\beta$-blockers}

Among 1,614 patients in the $\beta$ group, carvedilol was prescribed in 1,456 patients (90.2\%). The median dose of carvedilol in the current study population was 5 (range: $0.25-60.0$ ) mg per day. Among 1,456 patients with carvedilol, $385(26.5 \%)$ received carvedilol $\geq 10 \mathrm{mg}$ per day, while 1,071 (73.6\%) received $<10 \mathrm{mg}$ per day (Supplemental Table 4). Crude incidence of 3-year cardiac death/MI was significantly lower in patients who received carvedilol $\geq 10 \mathrm{mg}$ per day than in patients who received carvedilol $<10 \mathrm{mg}$ per day $(4.7 \%$ vs. $8.9 \%, \log$-rank $\mathrm{p}=0.02$, Supplemental Table 5$)$. However, after adjusting for clinically relevant risk-adjusting variables, the risk for cardiac death/MI was not significantly different (adjusted HR 0.65, 95\% CI: 0.38-1.05, $\mathrm{p}=0.08$, Supplemental Table 5).

\section{Sensitivity Analyses}

Propensity score of prescription of $\beta$-blockers was calculated using 24 clinically relevant variables (listed in Supplemental Table 6). In the propensity-score matched model, no significant differences in the baseline characteristics were found between the $\beta$ and no- $\beta$ groups, except that patients in the $\beta$ group more frequently had prior HF and shock at presentation (Supplemental Table 6). There was no significant difference in the 3-year incidence of cardiac death/MI 
between the $\beta$ and no- $\beta$ groups in this model (7.6\% vs. $6.1 \%, \log$-rank $p=0.2$, Supplemental Table 7). However, more hospitalizations for HF were observed in the $\beta$-group (7.2\% vs. 3.9\%, log-rank $\mathrm{p}<0.0001)$ (Supplemental Table 7).

\section{Discussion}

The major findings of this recent registry analyses were as follows: (1) the 3-year cardiovascular event rate of patients who underwent PCI after STEMI was relatively low; (2) $\beta$-blocker prescription at discharge was not associated with better cardiovascular outcomes in these patients.

Despite the recommendations of the clinical guidelines, $\beta$-blocker use in STEMI has been less prevalent in the real-world clinical practice. ${ }^{11}$ In the current study population, only $43.7 \%$ of patients received oral $\beta$-blocker therapy at discharge. That was less than the frequencies of $\beta$-blocker prescription reported from the PAMI study conducted in the USA $(68.0 \%),{ }^{5}$ but similar to the rate reported in the Heart Institute of Japan Acute Myocardial Infarction registry (HIJAMI) study (32.2\%) and the j-Cypher study (38.4\%) conducted in Japan. ${ }^{6,12}$

The main mechanisms of the beneficial effects of $\beta$-blockers in patients with STEMI are considered to be the prevention of the cardiotoxic effects of catecholamines and the attenuation of the myocardial oxygen demand. $\beta$-blockers are also thought to be effective in reducing tachyarrhythmic events. Previous studies conducted in the pre-PCI era

showed markedly lower mortality rate with $\beta$-blocker therapy in STEMI patients. ${ }^{3,4}$ However, in the present study, relatively low 3-year cardiovascular event rate was observed despite the low prescription rate of $\beta$-blockers at discharge. In addition to the preserved LVEF in most STEMI patients who have undergone emergent PCI, the high use of up-to-date medications such as ACE-I /angiotensin receptor blockers and statins may result in the improved clinical outcomes of these patients. On the other hand, the adverse effects of $\beta$-blockers such as coronary spasm should be considered in these 
patients as they are disadvantageous. In the Japanese $\beta$-blocker and Calcium Antagonist Myocardial Infarction (JBCMI)

study, the incidence of coronary spasm was significantly higher in patients with $\beta$-blocker therapy than those with calcium antagonist therapy $(1.2 \%$ vs. $0.2 \%, \mathrm{p}=0.02)$, but no significant difference was observed in cardiac mortality (1.7\% vs. $1.1 \%, \mathrm{p}=0.37) .{ }^{13}$ It's important to note that a majority of STEMI patients have hypertension $(85.9 \%$ of patients in the $\beta$ group had hypertension in the present study) and the adverse effects of $\beta$-blockers have been a concern in patients with hypertension on the basis of recent clinical trials. ${ }^{14-16}$

\section{Study limitations}

Our study has several important limitations. First, $90.2 \%$ of the $\beta$-blockers prescribed were carvedilol in the present study. The impacts of different types of $\beta$-blockers on clinical outcomes were difficult to compare. However, carvedilol, a nonselective $\beta$-blocker with alpha 1-adrenergic receptor blocking and antioxidant effects, has been reported to have superior cardioprotective effects compared to other $\beta$-blockers on reducing the risk of events after AMI. ${ }^{17,18}$ Second, the relatively low dose of $\beta$-blockers prescribed could be one of the reasons why $\beta$-blockers were not associated with better clinical outcomes in this study. The median dose of carvedilol was $5 \mathrm{mg}$ per day in this study, which was lower than the dose previously reported. In the Carvedilol Post-Infarct Survival Control in LV Dysfunction (CAPRICORN) trial, 12.5-50 mg per day of carvedilol reduced all-cause mortality, cardiovascular-cause mortality, and reinfarction when given to patients with recent AMI and LVEF $\leq 40 \% .{ }^{19}$ Another study reported that Carvedilol produced dose-related reductions in mortality and hospitalization rate in patients with HF. ${ }^{20}$ In the current analysis, use of higher-dose carvedilol ( $\geq 10 \mathrm{mg}$ per day) was associated with a tendency of better clinical outcomes compared with use of lower-dose carvedilol (< $10 \mathrm{mg}$ per day) in a risk-adjusted model $(\mathrm{p}=0.08)$. However, the relatively low dose of $\beta$-blockers 
prescribed in the study patients was probably attributed to the physical and racial differences of the study patients.

Japanese patients had lower body weight compared to the American patients. The median body weight of the Japanese

STEMI patients observed in the $\beta$ group in this study was 62 (IQR: 54-70) $\mathrm{kg}$, which is obviously lower compared to the

American STEMI patients at 80 (IQR: 70-91) kg. ${ }^{21}$ In addition, Asian patients are predisposed to hypotension and bradycardia with high-dose $\beta$-blockers. ${ }^{22}$ According to investigations conducted in Japan, the approved dose of carvedilol for the treatment of hypertension, coronary artery disease, and HF is 2.5 to $20 \mathrm{mg}$ per day for Japanese patients.

${ }^{23}$ Thus, the dose of $\beta$-blockers used in this study is thought to be reasonable for the study patients and it definitely reflected the real-world clinical practice in Japan. Third, we do not have information on which patients in the $\beta$ group continued $\beta$-blockers during the years after discharge. Prescription of $\beta$-blockers at discharge might not be representative of long-term use of $\beta$-blockers after STEMI. However, previous studies reported that $>80 \%$ of patients continued to receive $\beta$-blockers 6 months after AMI. ${ }^{24}$ In addition, patients not discharged on $\beta$-blockers are unlikely to be started on them as outpatients. ${ }^{25}$ Forth, the current study did not have adequate power to assess outcomes in the subgroup with low LVEF. In this study, the use of $\beta$-blockers was not associated with better clinical outcomes in patients with low LVEF. The current result in the low-LVEF subgroup was inconsistent with the previous report from the j-Cypher registry that showed $\beta$-blockers after primary PCI were associated with reduced 3-year mortality in a subgroup of patients with low LVEF. ${ }^{6}$ It was also inconsistent with the PAMI study in which $\beta$-blockers were associated with lower 6-month mortality in patients with LVEF $\leq 50 \% .{ }^{5}$ Although all of these studies are observational and including relatively small number of patients with low LVEF, beneficial effect of $\beta$-blocker for STEMI patients with low LVEF has been reported in a large-scale randomized controlled trial in which about a half of the patients underwent reperfusion therapy mainly by 
thrombolytic therapy. ${ }^{19}$ Finally, selection bias for use of $\beta$-blockers is inevitable in this type of observational study.

Although we included potential confounders in the multivariable Cox proportional-hazards models and we tried to minimize the difference of baseline characteristics between patients in the $\beta$ and no- $\beta$ groups with propensity matching in the sensitivity analyses, we could not exclude influences of unmeasured confounders on clinical outcomes. The effect of $\beta$-blockers in patients with STEMI after successful PCI should be evaluated by a randomized controlled study with a large sample size.

\section{Conclusions}

In this study, oral $\beta$-blocker prescription at discharge was not associated with better cardiovascular outcomes in patients who underwent PCI after STEMI. Most of these patients had preserved LVEF and fair prognosis without $\beta$-blocker use. Large-scale randomized controlled trials are needed to evaluate the role of $\beta$-blocker therapy in these patients.

\section{Acknowledgments}

All authors have contributed to the design of the study, interpretation of results, revising the manuscript, and approve the final version of the manuscript. We thank the members of the cardiac catheterization laboratories of the participating centers and the clinical research coordinators (Supplemental Appendix).

This study was supported by the Pharmaceuticals and Medical Devices Agency (PMDA) in Japan.

Conflict of interest: none declared. 


\section{References}

1. Antman EM, Anbe DT, Armstrong PW, Bates ER, Green LA, Hand M, et al. ACC/AHA guidelines for the management of patients with ST-elevation myocardial infarction--executive summary: a report of the American College of Cardiology/American Heart Association Task Force on Practice Guidelines (Writing Committee to Revise the 1999 Guidelines for the Management of Patients With Acute Myocardial Infarction). Circulation 2004;110:588-636.

2. Van de Werf F, Bax J, Betriu A, Blomstrom-Lundqvist C, Crea F, Falk V, et al. Management of acute myocardial infarction in patients presenting with persistent ST-segment elevation: the Task Force on the Management of ST-Segment Elevation Acute Myocardial Infarction of the European Society of Cardiology. Eur Heart $J$ 2008;29:2909-45.

3. Beta-blocker Heart Attack Study Group. The Beta-blocker Heart-Attack Trial. JAMA 1981;246:2073-4.

4. Freemantle N, Cleland J, Young P, Mason J, Harrison J. $\beta$ blockade after myocardial infarction: systematic review and meta regression analysis. BMJ 1999;318:1730-7.

5. Kernis SJ, Harjai KJ, Stone GW, Grines LL, Boura JA, O'Neill WW, et al. Does $\beta$-blocker therapy improve clinical outcomes of acute myocardial infarction after successful primary angioplasty? J Am Coll Cardiol 2004;43:1773-9.

6. Ozasa N, Kimura T, Morimoto T, Hou H, Tamura T, Shizuta S, et al. Lack of Effect of Oral $\beta$-Blocker Therapy at Discharge on Long-Term Clinical Outcomes of ST-Segment Elevation Acute Myocardial Infarction After Primary Percutaneous Coronary Intervention. Am J Cardiol 2010;106:1225-33.

7. Serruys PW, Ong ATL, van Herwerden LA, Sousa JE, Jatene A, Bonnier JJRM, et al. Five-year outcomes after 
coronary stenting versus bypass surgery for the treatment of multivessel disease - The final analysis of the arterial revascularization therapies study (ARTS) randomized trial. J Am Coll Cardiol 2005;46:575-81.

8. Kimura T, Morimoto T, Nakagawa Y, Tamura T, Kadota K, Yasumoto H,et al. Antiplatelet Therapy and Stent Thrombosis After Sirolimus-Eluting Stent Implantation. Circulation 2009;119:987-U120.

9. Ghali WA, Quan H, Brant R, van Melle G, Norris CM, Faris PD, et al. Comparison of 2 methods for calculating adjusted survival curves from proportional hazards models. JAMA 2001;286:1494-7.

10. Parsons LS. Reducing bias in a propensity score matched pair sample using greedy matching techniques. In: Proceedings of the 26th Annual SAS Users Group International Conference. Cary, NC: SAS Institute Inc.; 2001.

11. Kohro T, Hayashi D, Yamazaki T, Nagai R; JCAD Investigators. Beta-blocker prescription among Japanese cardiologists and its effect on various outcomes. Circ J. 2010;74: 962-9.

12. Kasanuki H, Honda T, Haze K, Sumiyoshi T, Horie T, Yagi M,et al. A large-scale prospective cohort study on the current status of therapeutic modalities for acute myocardial infarction in Japan: rationale and initial results of the HIJAMI Registry. Am Heart J 2005;150:411-8.

13. The Japanese $\beta$-blockers and Calcium Antagonists Myocardial Infarction (JBCMI) Investigators. Comparison of the effects of $\beta$ blockers and calcium antagonists on cardiovascular events after acute myocardial infarction in Japanese subjects. Am J Cardiol 2004;93:969-73.

14. Dahlof B, Devereux RB, Kjeldsen SE, Julius S, Beevers G, de Faire U, et al. Cardiovascular morbidity and mortality in the Losartan Intervention For Endpoint reduction in hypertension study (LIFE): a randomised trial against atenolol. Lancet 2002;359:995-1003. 
15. Dahlof B, Sever PS, Poulter NR, Wedel H, Beevers DG, Caulfield M, et al. Prevention of cardiovascular events with an antihypertensive regimen of amlodipine adding perindopril as required versus atenolol adding bendroflumethiazide as required, in the Anglo-Scandinavian Cardiac Outcomes Trial-Blood Pressure Lowering Arm (ASCOT-BPLA): a multicentre randomised controlled trial. Lancet 2005;366:895-906.

16. Lindholm LH, Carlberg B, Samuelsson O. Should $\beta$ blockers remain first choice in the treatment of primary hypertension? A meta-analysis. Lancet 2005;366:1545-53.

17. Kopecky SL. Effect of $\beta$ blockers, particularly carvedilol, on reducing the risk of events after acute myocardial infarction. Am J Cardiol 2006;98:1115-9.

18. Cimmino G, Ibanez B, Giannarelli C, Prat-Gonzalez S, Hutter R, Garcia M, Sanz J, Fuster V, Badimon JJ. Carvedilol administration in acute myocardial infarction results in stronger inhibition of early markers of left ventricular remodeling than metoprolol. Int J Cardiol 2011;153:256-61.

19. Dargie HJ. Effect of carvedilol on outcome after myocardial infarction in patients with left-ventricular dysfunction: the CAPRICORN randomised trial. Lancet 2001;357:1385-90.

20. Bristow MR, Gilbert EM, Abraham WT, Adams KF, Fowler MB, Hershberger RE, et al. Carvedilol produces dose-related improvements in left ventricular function and survival in subjects with chronic heart failure. MOCHA Investigators. Circulation 1996;94:2807-16.

21. Mehta RH, Starr AZ, Lopes RD, Hochman JS, Widimsky P, Pieper KS, et al. Incidence of and outcomes associated with ventricular tachycardia or fibrillation in patients undergoing primary percutaneous coronary intervention. 
22. Xie HG, Kim RB, Wood AJ, Stein CM. Molecular basis of ethnic differences in drug disposition and response.

Annu Rev Pharmacol Toxicol 2001;41:815-50.

23. Hori M, Sasayama S, Kitabatake A, Toyo-oka T, Handa S, Yokoyama M, et al. Low-dose carvedilol improves left ventricular function and reduces cardiovascular hospitalization in Japanese patients with chronic heart failure: the Multicenter Carvedilol Heart Failure Dose Assessment (MUCHA) trial. Am Heart J 2004;147:324-30.

24. Ho PM, Spertus JA, Masoudi FA, Reid KJ, Peterson ED, Magid DJ, et al Impact of medication therapy discontinuation on mortality after myocardial infarction. Arch Intern Med 2006;166:1842-7.

25. Butler J, Arbogast PG, BeLue R, Daugherty J, Jain MK, Ray WA, et al. Outpatient adherence to $\beta$-blocker therapy after acute myocardial infarction. J Am Coll Cardiol 2002;40:1589-95.

The final publication is available at Springer via http://link.springer.com/article/10.1007/s12928-012-0137-9 


\section{Figure Legends}

Figure 1. Study Flow Chart.

$\mathrm{CABG}=$ coronary artery bypass surgery, $\mathrm{PCI}=$ percutaneous coronary intervention, and STEMI $=$ ST - segment elevation myocardial infarction.

Figure 2. Cardiac Death/MI Rates in the Study Population.

Crude and adjusted cumulative incidence curves for cardiac death/MI among patients treated with or without $\beta$-blockers in the entire cohort (A), in the preserved LVEF subgroup (B), and in the low LVEF subgroup (C).

LVEF $=$ left ventricular ejection fraction, $\mathrm{PCI}=$ percutaneous coronary intervention. 
Table 1. Baseline Clinical Characteristics, Procedural Characteristics and Baseline Medications in All

Patients

B group No- $\beta$ group $\quad$ p

$\mathrm{N}=\mathbf{1 , 6 1 4} \quad \mathrm{N}=\mathbf{2 , 0 7 8}$ value

\section{(A) Clinical characteristics}

\begin{tabular}{|c|c|c|c|}
\hline Age (years) & $65.8 \pm 12.2$ & $68.0 \pm 12.1$ & $<0.0001$ \\
\hline$*$ Age $\geq 75$ years & $416(25.8 \%)$ & $668(32.1 \%)$ & $<0.0001$ \\
\hline *Male & $1,255(77.8 \%)$ & $1,500(72.2 \%)$ & 0.0001 \\
\hline Body weight (kg) & $62.4(54.2-70.0)+$ & $60.0(53.0-68.0) \ddagger$ & $<0.0001 \dagger$ \\
\hline BMI & $23.5(21.5-25.9)$ & $23.3(21.3-25.3)$ & $0.0008 \uparrow$ \\
\hline$* \mathrm{BMI}<25.0$ & $1,103(68.3 \%)$ & $1,529(73.6 \%)$ & 0.0005 \\
\hline Onset-to-balloon time (hours) & $4.1(2.7-6.7) \S$ & $4.3(2.9-7.6) \S$ & $0.002 \dagger$ \\
\hline Onset-to-balloon time $\leq 6$ hours & $987(70.4 \%) \S$ & $1,237(67.3 \%) \S$ & 0.06 \\
\hline Door-to-balloon time (hours) & $1.5(1.0-2.2) \|$ & $1.5(1.0-2.2) \|$ & $0.24 \dagger$ \\
\hline *Anterior infarction & $850(52.7 \%)$ & $955(46.0 \%)$ & $<0.0001$ \\
\hline *Hypertension & $1,386(85.9 \%)$ & $1,521(73.2 \%)$ & $<0.0001$ \\
\hline Diabetes mellitus & $494(30.6 \%)$ & $667(32.1 \%)$ & 0.33 \\
\hline *on insulin therapy & $58(3.6 \%)$ & $92(4.4 \%)$ & 0.2 \\
\hline
\end{tabular}


Table 1. Baseline Clinical Characteristics, Procedural Characteristics and Baseline Medications in All

Patients (cont)

*Current smoking

*Heart failure

*Shock at presentation

*Multivessel disease

* Mitral regurgitation grade 3/4

$\operatorname{LVEF}(\%)$

$\mathrm{LVEF} \leq 40 \%$

*Prior myocardial infarction

*Prior stroke

*Peripheral vascular disease

*eGFR < 30ml/min, not on dialysis

*Dialysis

*Atrial fibrillation

*Anemia $(\mathrm{Hb}<11.0 \mathrm{~g} / \mathrm{dl})$

*Platelet $<100 * 109 / \mathrm{L}$

*COPD

*Liver cirrhosis
$686(42.5 \%)$

$452(28.0 \%)$

$234(14.5 \%)$

$814(50.4 \%)$

$38(2.4 \%)$

$52.4 \pm 12.6 \#$

$228(16.7 \%) \#$

$140(8.7 \%)$

$121(7.5 \%)$

$45(2.8 \%)$

$50(3.1 \%)$

$24(1.5 \%)$

$163(10.1 \%)$

$133(8.2 \%)$

$28(1.7 \%)$

$31(1.9 \%)$

$43(2.7 \%)$
$850(40.9 \%)$

0.32

$556(26.8 \%) \quad 0.39$

$268(12.9 \%) \quad 0.15$

$1,048(50.4 \%) \quad 0.99$

$53(2.6 \%)$

0.7

$54.3 \pm 12.2 \# \quad<0.0001$

$222(14.1 \%) \# \quad 0.04$

$177(8.5 \%) \quad 0.86$

$194(9.3 \%) \quad 0.04$

$60(2.9 \%) \quad 0.85$

$70(3.4 \%) \quad 0.64$

$21(1.0 \%)$

0.19

$171(8.2 \%) \quad 0.04$

$172(8.3 \%) \quad 0.96$

$27(1.3 \%) \quad 0.27$

$94(4.5 \%) \quad<0.0001$

$46(2.2 \%) \quad 0.37$ 
Table 1. Baseline Clinical Characteristics, Procedural Characteristics and Baseline Medications in All

Patients (cont)

*Malignancy

$117(7.3 \%)$

$175(8.4 \%)$

0.19

\section{(B) Procedural characteristics}

*DES use

Number of target lesions

*Target of proximal LAD

*Target of unprotected LMCA

*Target of CTO

*Target of bifurcation

*Side-branch stenting

Total number of stents

Total stent length (mm)

*Total stent $>28 \mathrm{~mm}$

Minimum stent size (mm)

*Minimum stent size $<3.0 \mathrm{~mm}$

\section{(C) Discharge Medication}

Antiplatelet therapy

Thienopyridine
$480(29.7 \%)$

$1(1-2)$

$947(58.7 \%)$

$42(2.6 \%)$

$51(3.2 \%)$

$414(25.7 \%)$

$45(2.8 \%)$

$1(1-2) \#$

$25(18-43) * *$

$663(44.3 \%) * *$

$3(2.5-3.5) * *$

$479(32.0 \%) * *$

$589(31.0 \%) * *$

0.51

$614(29.5 \%) \quad 0.89$

$1(1-2)$

$0.17 \dagger$

$1,055(50.8 \%) \quad<0.0001$

$48(2.3 \%) \quad 0.56$

$58(2.8 \%) \quad 0.51$

$530(25.5 \%) \quad 0.92$

$62(3.0 \%) \quad 0.72$

$1(1-2) \# \quad 0.42 \dagger$

$24(18-42) * * \quad 0.03 \dagger$

$799(42.0 \%) * * \quad 0.18$

$3(2.5-3.5) * * \quad 0.42 \dagger$

$1,565(97.0 \%) \quad 1,998(96.1 \%) \quad 0.18$ 
Table 1. Baseline Clinical Characteristics, Procedural Characteristics and Baseline Medications in All

Patients (cont)

Ticlopidine

Clopidogrel

Aspirin

*Cilostazol

Other medications

*Statins

*ACE-I/ARB

*Nitrates

*Calcium channel blockers

*Nicorandil

*Warfarin

*Proton pump inhibitors

*H2-blockers
$1,426(88.4 \%)$

$139(8.6 \%)$

$1,608(99.6 \%)$

$541(33.5 \%)$

$1,034(64.1 \%)$

$1,342(83.2 \%)$

$421(26.1 \%)$

$333(20.6 \%)$

$488(30.2 \%)$

$238(14.8 \%)$

$588(36.4 \%)$

$533(33.0 \%)$
$1,838(88.5 \%)$

0.92

$159(7.7 \%) \quad 0.28$

$2,064(99.3 \%) \quad 0.21$

$770(37.1 \%) \quad 0.02$

Variables are mean $\pm \mathrm{SD}, \mathrm{n}(\%)$, or median (IQR). *Clinically relevant risk adjusting variables selected for multivariable Cox proportional-hazards model for $\beta$-blocker therapy. 
$\dagger$ Wilcoxon $\mathrm{p}$ value.

\$ Values were missing for body weight (kg) in 107 patients, 30 in $\beta$ group and 77 in no- $\beta$ group.

$\S$ Values were missing for onset-to-balloon time (hours) in 453 patients, 212 in $\beta$ group and 241 in no- $\beta$ group.

|| Values were missing for door-to-balloon time (hours) in 495 patients, 240 in $\beta$ group and 255 in no- $\beta$ group.

\# Values were missing for LVEF in 748 patients, 249 in $\beta$ group and 499 in no- $\beta$ group.

** Exclude 292 patients without stent implantation, 117 in $\beta$ group and 175 in no- $\beta$ group.

$\mathrm{ACE}-\mathrm{I}=$ angiotensin converting enzyme inhibitor, $\mathrm{ARB}=$ angiotensin receptor blocker, $\mathrm{BMI}=$ body mass

index, $\mathrm{COPD}=$ chronic obstructive pulmonary disease, $\mathrm{DES}=$ drug-eluting stent, $\mathrm{CTO}=$ chronic total occlusion, $\mathrm{eGFR}=$ estimated glomerular filtration rate, $\mathrm{H} 2$-blocker $=$ histamine type 2 receptor blocker, $\mathrm{LAD}=$ left anterior descending coronary artery, LMCA = left main coronary artery, and LVEF = left ventricular ejection fraction. 
Table 2. Crude Event Rates and Adjusted Hazard Ratio Through 3 Years

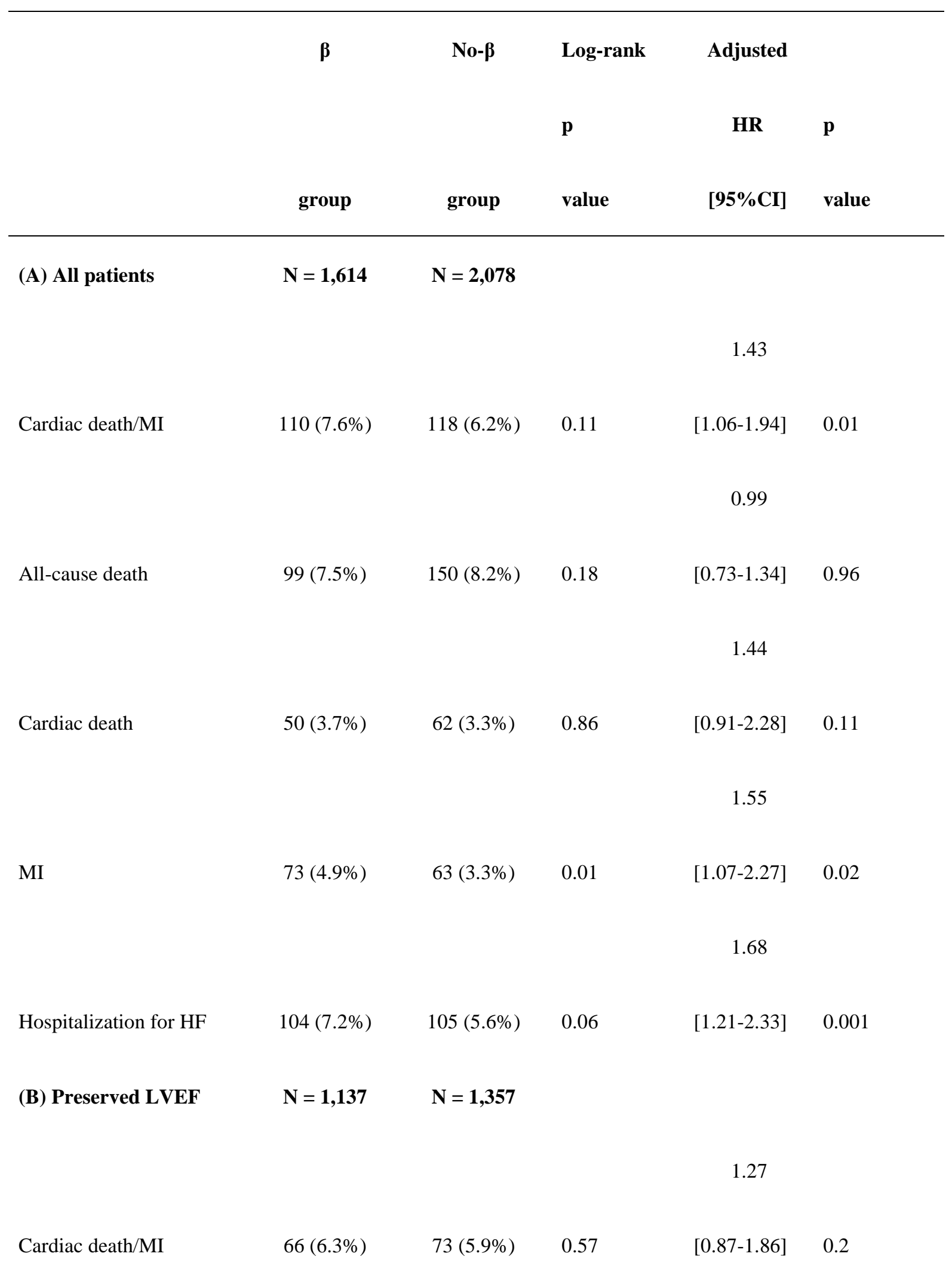


Table 2. Crude Event Rates and Adjusted Hazard Ratio Through 3 Years (cont)

0.87

All-cause death

Cardiac death

MI

(C) Low LVEF

Cardiac death/MI

$29(15.5 \%)$

$33(17.0 \%)$

0.35

[0.76-4.34]

0.17

Cardiac death

$19(10.3 \%)$

$18(8.9 \%)$

0.86

$[0.65-7.41] \quad 0.20$

MI

$11(5 \cdot 2 \%)$

$4(2.0 \%)$

0.04

1.26 
Incidences at 3 years were estimated by the Kaplan-Meier method.

* Adjusted HR of MI in low LVEF group could not be evaluated.

$\mathrm{CI}=$ confidence interval, $\mathrm{HF}=$ heart failure, $\mathrm{HR}=$ hazard ratio, $\mathrm{LVEF}=$ left ventricular ejection fraction, and $\mathrm{MI}=$ myocardial infarction . 
Figure1.

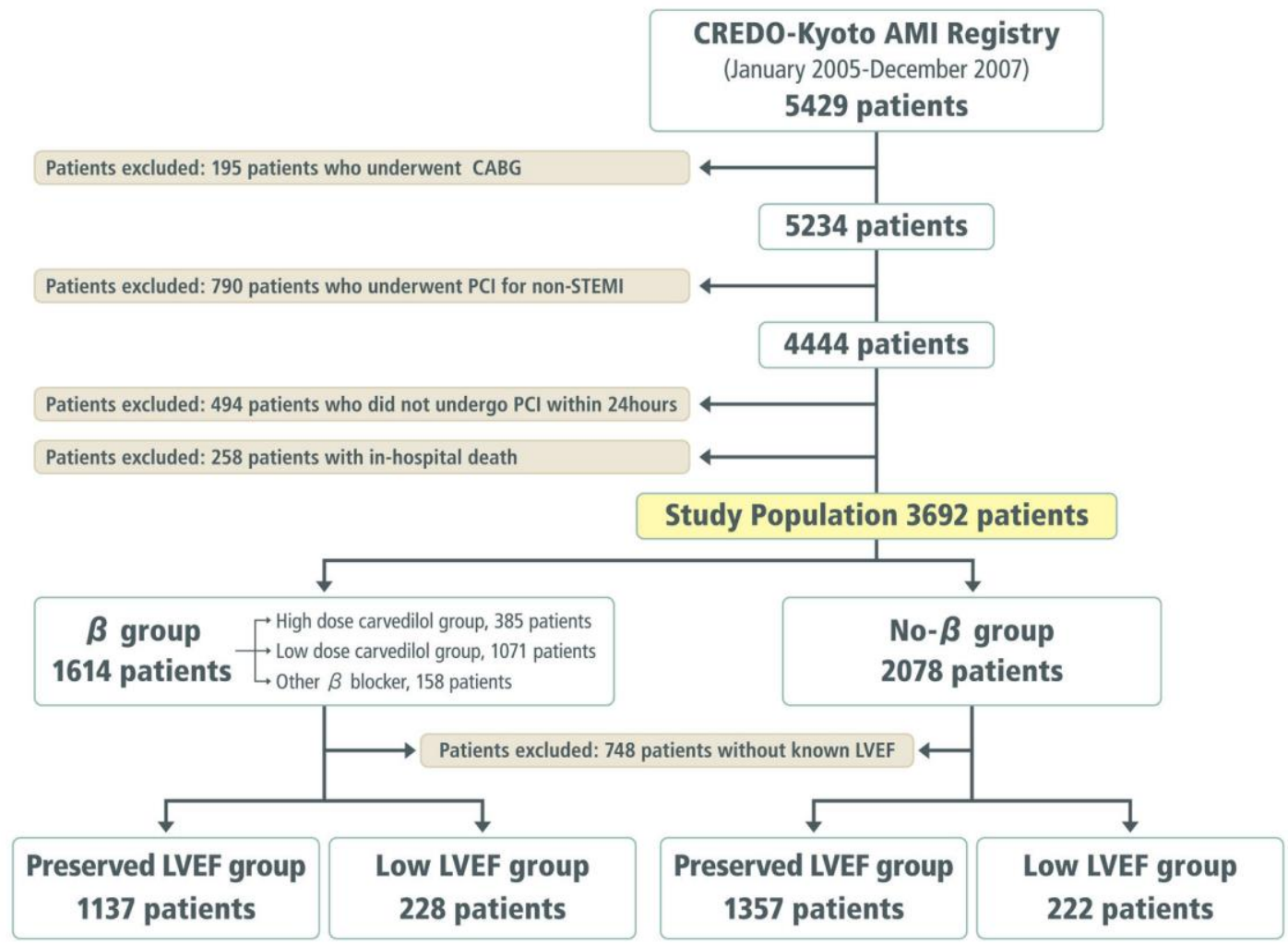


Figure 2.

Cardiac death / Myocardial infarction
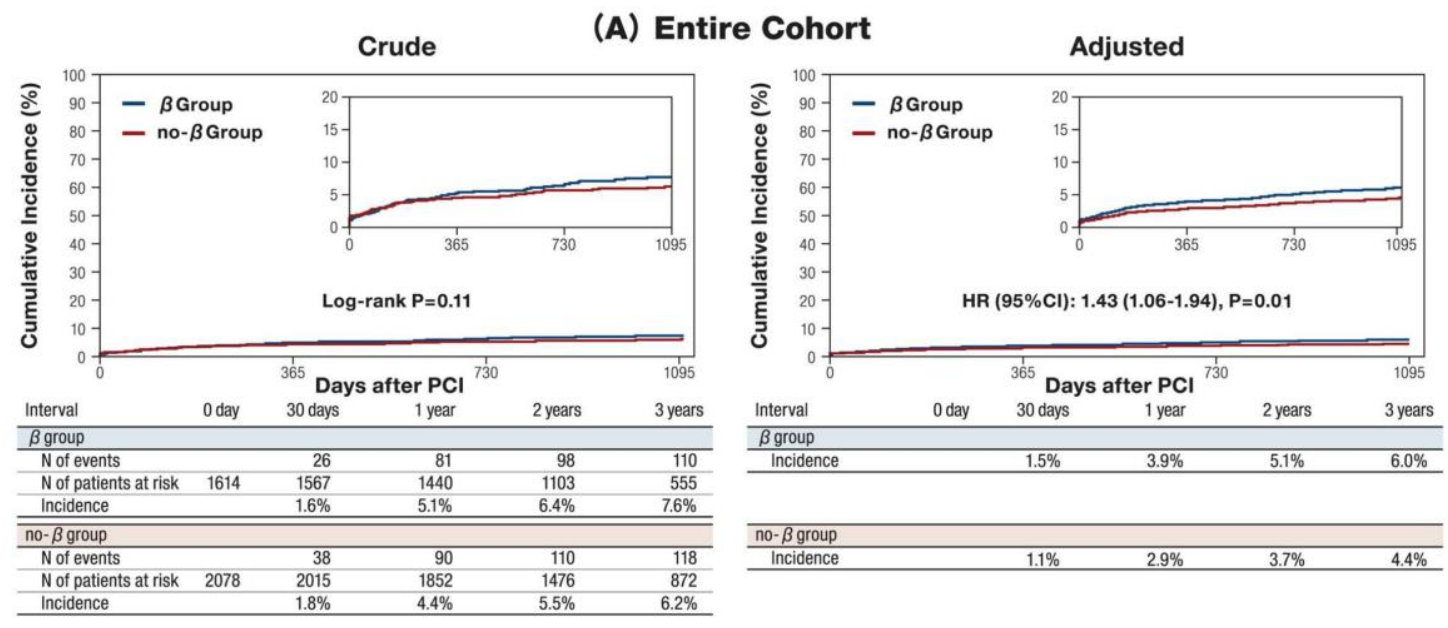

Crude

(B) Preserved LVEF
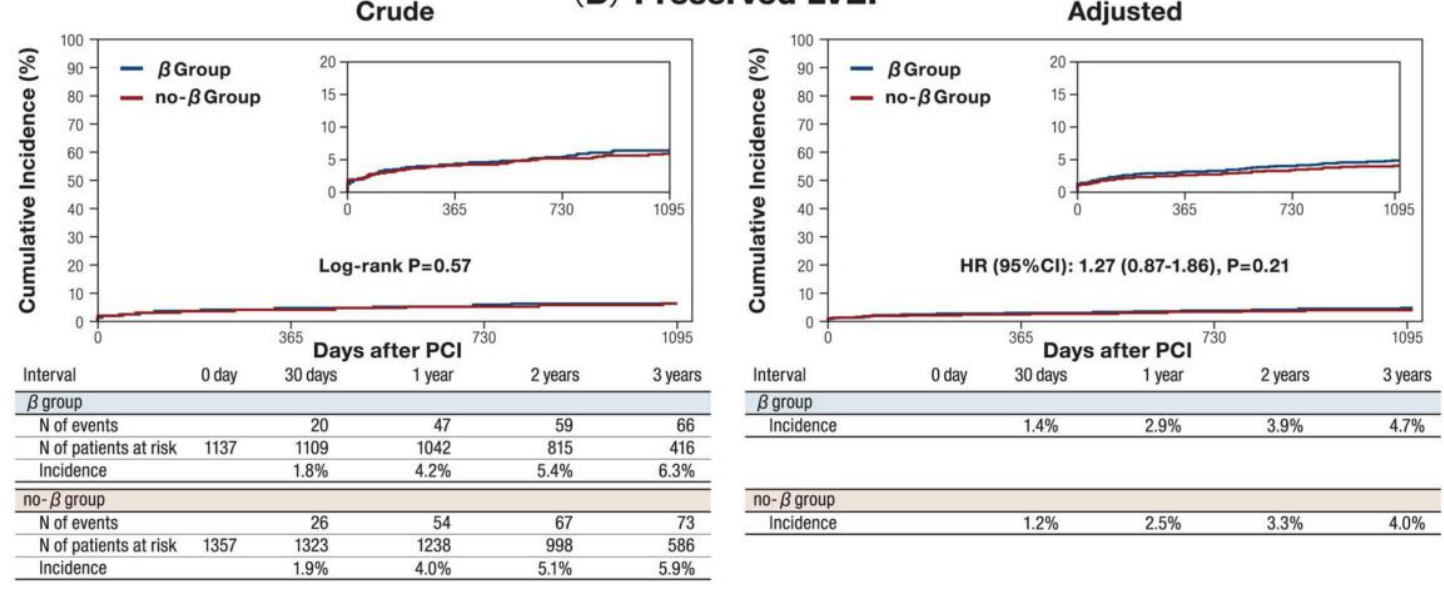

Crude

(C) Low LVEF
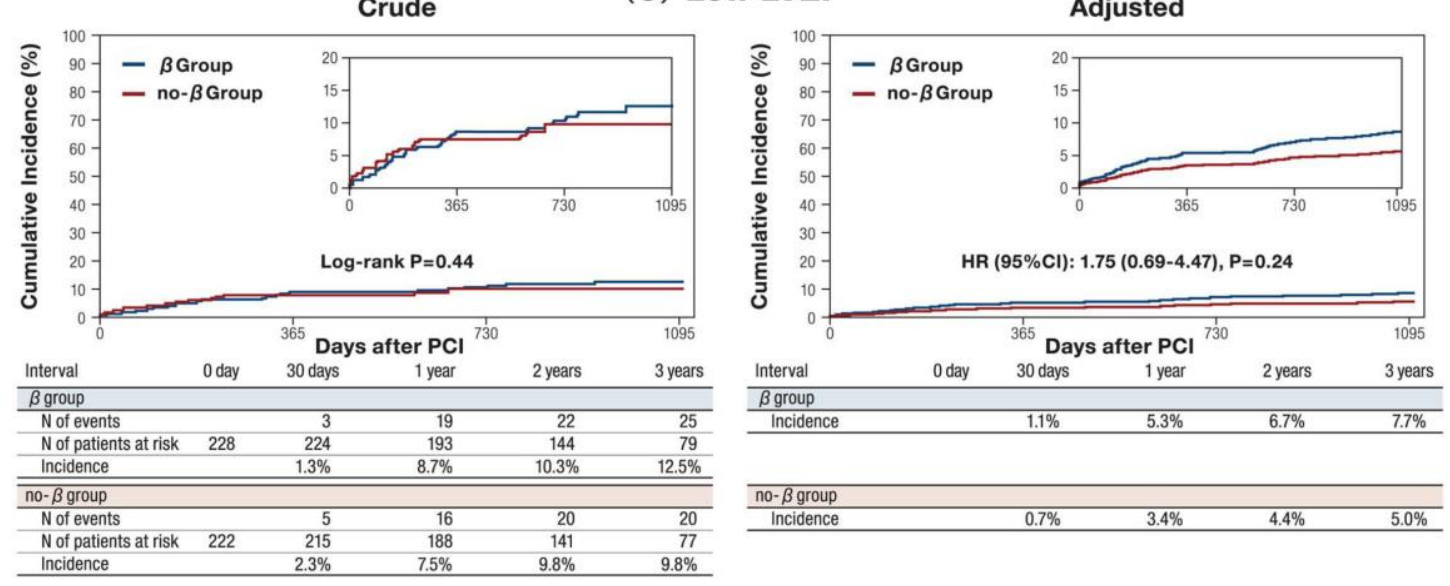


\section{SUPPLEMENTAL MATERIAL.}

Supplemental Appendix A: List of Participating Centers and Investigators for the CREDO-Kyoto AMI

\section{Registry Cohort-2}

\section{Cardiology}

Kyoto University Hospital: Takeshi Kimura

Kishiwada City Hospital: Mitsuo Matsuda, Hirokazu Mitsuoka

Tenri Hospital: Yoshihisa Nakagawa

Hyogo Prefectural Amagasaki Hospital: Hisayoshi Fujiwara, Yoshiki Takatsu, Ryoji Taniguchi

Kitano Hospital: Ryuji Nohara

Koto Memorial Hospital: Tomoyuki Murakami, Teruki Takeda

Kokura Memorial Hospital: Masakiyo Nobuyoshi, Masashi Iwabuchi

Maizuru Kyosai Hospital: Ryozo Tatami

Nara Hospital, Kinki University Faculty of Medicine: Manabu Shirotani

Kobe City Medical Center General Hospital: Toru Kita, Yutaka Furukawa, Natsuhiko Ehara

Nishi-Kobe Medical Center: Hiroshi Kato, Hiroshi Eizawa

Kansai Denryoku Hospital: Katsuhisa Ishii

Osaka Red Cross Hospital: Masaru Tanaka

University of Fukui Hospital: Jong-Dae Lee, Akira Nakano 
Shizuoka City Shizuoka Hospital: Akinori Takizawa

Hamamatsu Rosai Hospital: Masaaki Takahashi

Shiga University of Medical Science Hospital: Minoru Horie, Hiroyuki Takashima

Japanese Red Cross Wakayama Medical Center: Takashi Tamura

Shimabara Hospital: Mamoru Takahashi

Kagoshima University Medica and Dental Hospital: Chuwa Tei, Shuichi Hamasaki

Shizuoka General Hospital: Hirofumi Kambara, Osamu Doi, Satoshi Kaburagi

Kurashiki Central Hospital: Kazuaki Mitsudo, Kazushige Kadota

Mitsubishi Kyoto Hospital: Shinji Miki, Tetsu Mizoguchi

Kumamoto University Hospital: Hisao Ogawa, Seigo Sugiyama

Shimada Municipal Hospital: Ryuichi Hattori, Takeshi Aoyama, Makoto Araki

Juntendo University Shizuoka Hospital: Satoru Suwa

\section{Cardiovascular Surgery}

Kyoto University Hospital: Ryuzo Sakata, Tadashi Ikeda, Akira Marui

Kishiwada City Hospital: Masahiko Onoe

Tenri Hospital: Kazuo Yamanaka

Hyogo Prefectural Amagasaki Hospital: Keiichi Fujiwara, Nobuhisa Ohno

Kokura Memorial Hospital: Michiya Hanyu 
Maizuru Kyosai Hospital: Tsutomu Matsushita

Nara Hospital, Kinki University Faculty of Medicine: Noboru Nishiwaki, Yuichi Yoshida

Kobe City Medical Center General Hospital: Yukikatsu Okada, Michihiro Nasu

Osaka Red Cross Hospital: Shogo Nakayama

University of Fukui Hospital: Kuniyoshi Tanaka, Takaaki Koshiji, Koichi Morioka

Shizuoka City Shizuoka Hospital: Mitsuomi Shimamoto, Fumio Yamazaki

Hamamatsu Rosai Hospital: Junichiro Nishizawa

Japanese Red Cross Wakayama Medical Center: Masaki Aota

Shimabara Hospital: Takafumi Tabata

Kagoshima University Medica and Dental Hospital: Yutaka Imoto, Hiroyuki Yamamoto

Shizuoka General Hospital: Katsuhiko Matsuda, Masafumi Nara

Kurashiki Central Hospital: Tatsuhiko Komiya

Mitsubishi Kyoto Hospital: Hiroyuki Nakajima

Kumamoto University Hospital: Michio Kawasuji, Syuji Moriyama

Juntendo University Shizuoka Hospital: Keiichi Tanbara

\section{Supplemental Appendix B: List of Clinical Research Coordinators}

Research Institute for Production Development: Kumiko Kitagawa, Misato Yamauchi, Naoko Okamoto, Yumika Fujino, Saori Tezuka, Asuka Saeki, Miya Hanazawa, Yuki Sato, Chikako Hibi, Hitomi Sasae, Emi 
Takinami, Yuriko Uchida, Yuko Yamamoto, Satoko Nishida, Mai Yoshimoto, Sachiko Maeda, Izumi Miki,

Saeko Minematsu. 
Supplemental Table 1. Multivariable Cox Proportional-hazards Model for 3-year Risk of

\section{Cardiac Death/MI}

\section{Hazard Ratio}

$95 \%$ CI

p value

$\beta$-blockers

1.43

$1.06-1.94$

0.01

Age $\geq 75$ years

$1.51-2.86$

$<0.0001$

Male

0.97

$0.69-1.37$

0.87

BMI $<25.0$

1.17

$0.84-1.65$

0.35

Anterior infarction

1.25

$0.83-1.88$

0.28

Hypertension

1.18

$0.81-1.71$

0.38

DM on insulin therapy

1.45

$0.84-2.50$

0.18

Current smoking

1.00-1.86

0.04

Heart failure

1.17

$0.80-1.73$

0.42

Shock at presentation

1.25

0.80-1.96

0.33

Multivessel disease

1.26

$0.92-1.73$

0.15

Mitral regurgitation grade 3/4

0.84

$0.38-1.87$

0.66

Prior myocardial infarction

1.64

$1.09-2.48$

0.01

Prior stroke

1.27

$0.82-1.97$

0.28 
Supplemental Table 1. Multivariable Cox Proportional-hazards Model for 3-year Risk of

\section{Cardiac Death/MI (cont)}

Peripheral vascular disease

1.48

$0.80-2.73$

0.2

eGFR $<30 \mathrm{ml} / \mathrm{min}$, not on dialysis

1.83

$1.07-3.15$

0.02

Dialysis

1.97

$0.75-5.20$

0.16

Atrial fibrillation

1.14

0.73-1.79

0.56

Anemia $(\mathrm{Hb}<11.0 \mathrm{~g} / \mathrm{dl})$

1.10

$0.71-1.70$

0.66

Platelet $<100 * 109 / \mathrm{L}$

2.23

$1.13-4.41$

0.02

COPD

2.39

$1.35-4.23$

0.002

Liver cirrhosis

0.99

$0.47-2.06$

0.97

Malignancy

1.37

$0.91-2.05$

0.13

DES use

0.62

0.40-0.96

0.03

Target of proximal LAD

1.09

$0.71-1.67$

0.69

Target of unprotected LMCA

1.42

$0.70-2.88$

0.33

Target of CTO

1.68

0.90-3.11

0.1

Target of bifurcation

0.92

$0.64-1.31$

0.63

Side-branch stenting

1.38

$0.71-2.68$

0.33

Total stent $>28 \mathrm{~mm}$

1.40

$1.01-1.93$

0.04 
Supplemental Table 1. Multivariable Cox Proportional-hazards Model for 3-year Risk of

\section{Cardiac Death/MI (cont)}

Minimum stent size $<3.0 \mathrm{~mm}$

1.16

$0.83-1.61$

0.39

Cilostazol

1.00

$0.64-1.56$

0.99

Statins

0.81

0.60-1.09

0.15

ACE-I/ARB

0.60

$0.43-0.83$

0.001

Nitrates

0.86

$0.60-1.23$

0.4

Calcium channel blockers

0.88

$0.62-1.25$

0.47

Nicorandil

0.97

$0.68-1.38$

0.85

Warfarin

1.18

$0.76-1.84$

0.45

Proton pump inhibitors

1.50

$1.06-2.12$

0.02

H2-blockers

1.16

$0.80-1.68$

0.43

$\mathrm{ACE}-\mathrm{I}=$ angiotensin converting enzyme inhibitor, $\mathrm{ARB}=$ angiotensin receptor blocker, $\mathrm{BMI}=$ body

mass index, $\mathrm{CI}=$ confidence interval, $\mathrm{COPD}=$ chronic obstructive pulmonary disease, $\mathrm{CTO}=$ chronic total occlusion, DES = drug-eluting stent, eGFR = estimated glomerular filtration rate,

H2-blocker = histamine type2 receptor blocker, LAD = left anterior descending coronary artery, $\mathrm{LMCA}=$ left main coronary artery, and MI = myocardial infarction. 
Supplemental Table 2. Baseline Clinical Characteristics, Procedural Characteristics and Baseline Medications in Patients with Preserved LVEF

\begin{tabular}{ccc}
\hline B group & No- $\beta$ group & $\mathbf{p}$ \\
$\mathrm{N}=1137$ & $\mathrm{~N}=1357$ & value \\
\hline
\end{tabular}

\section{(A) Clinical characteristics}

Age (years)

Age $\geq 75$ years

Male

Body weight $(\mathrm{kg})$

BMI

$\mathrm{BMI}<25.0$

Onset-to-balloon time (hours)

Onset-to-balloon time $\leq 6$ hours

Door-to-balloon time (hours)

Anterior infarction

Hypertension

Diabetes mellitus
$65.3 \pm 11.9$

$266(23.4 \%)$

$885(77.8 \%)$

$63(55-70)+$

$23.6(21.8-25.9)$

$765(67.3 \%)$

$4(2.7-6.6) \S$

$687(70.8 \%) \S$

$1.5(1.0-2.2) \|$

$1.5(1.0-2.2)$

$0.95^{*}$

$568(50.0 \%)$

$584(43.0 \%) \quad 0.0006$

$983(86.5 \%)$

$335(29.5 \%)$

$431(31.8 \%)$

0.21 
Supplemental Table 2. Baseline Clinical Characteristics, Procedural Characteristics and

Baseline Medications in Patients with Preserved LVEF (cont)

on insulin therapy

Current smoking

Heart failure

Shock at presentation

Multivessel disease

Mitral regurgitation grade 3/4

$\operatorname{LVEF}(\%)$

Prior myocardial infarction

Prior stroke

Peripheral vascular disease

eGFR $<30 \mathrm{ml} / \mathrm{min}$, not on dialysis

Dialysis

Atrial fibrillation

Anemia $(\mathrm{Hb}<11.0 \mathrm{~g} / \mathrm{dl})$

Platelet $<100 * 10^{9} / \mathrm{L}$

COPD
$35(3.1 \%)$

$491(43.2 \%)$

$248(21.8 \%)$

$120(10.6 \%)$

$565(49.7 \%)$

$20(1.8 \%)$

$55(49-63)$

$78(6.9 \%)$

$77(6.8 \%)$

$30(2.6 \%)$

$26(2.3 \%)$

$13(1.1 \%)$

$109(9.6 \%)$

$87(7.7 \%)$

$21(1.9 \%)$

$25(2.2 \%)$
$98(7.2 \%)$

$14(1.0 \%) \quad 0.08$

$59(4.4 \%) \quad 0.09$

$554(40.8 \%) \quad 0.23$

$296(21.8 \%) \quad 0.99$

$153(11.3 \%) \quad 0.56$

$673(49.6 \%) \quad 0.96$

$37(2.7 \%) \quad 0.1$

$57(50-65) \quad 0.0002 *$

$108(8.0 \%) \quad 0.29$

$106(7.8 \%) \quad 0.32$

$40(3.0 \%) \quad 0.64$

$35(2.6 \%) \quad 0.63$

$11(0.8 \%) \quad 0.39$

$104(7.7 \%) \quad 0.08$

0.68

$66(4.9 \%)<0.0001$ 
Supplemental Table 2. Baseline Clinical Characteristics, Procedural Characteristics and

Baseline Medications in Patients with Preserved LVEF (cont)

Liver cirrhosis

Malignancy

\section{(B) Procedural characteristics}

DES use

Number of target lesions

Target of proximal LAD

Target of unprotected LMCA

Target of CTO

Target of bifurcation

Side-branch stenting

Total number of stents

Total stent length (mm)

Total stent $>28 \mathrm{~mm}$

Minimum stent size (mm)

Minimum stent size $<3.0 \mathrm{~mm}$
$30(2.6 \%)$

$74(6.5 \%)$

$112(8.3 \%)$

0.09
$410(30.2 \%) \quad 0.9$

$1(1-2)$

$1(1-2)$

$0.21 *$

$647(56.9 \%)$

$659(48.6 \%)<0.0001$

$26(2.3 \%)$

$27(2.0 \%) \quad 0.6$

$31(2.7 \%)$

$37(2.7 \%) \quad 0.99$

$292(25.7 \%)$

$323(23.8 \%)$

0.27

$31(2.7 \%)$

$37(2.7 \%) \quad 0.99$

$1(1-2) \|$

$1(1-2) \|$

$0.65^{*}$

$25(18-43)$ \#

$24(18-43) \#$

$0.17 *$

$465(43.7 \%) \# \quad 526(42.0 \%) \# \quad 0.39$

$3(2.5-3.5)$

$3(2.5-3.5) \# \quad 0.61 *$

$332(31.2 \%) \# \quad 407(32.5 \%) \# \quad 0.52$ 
Supplemental Table 2. Baseline Clinical Characteristics, Procedural Characteristics and Baseline Medications in Patients with Preserved LVEF (cont)

(C) Discharge Medication

Antiplatelet therapy

Thienopyridine

Ticlopidine

Clopidogrel

Aspirin

Cilostazol

Other medications

Statins

ACE-I/ARB

Nitrates

Calcium channel blockers

Nicorandil

Warfarin

Proton pump inhibitors

H2-blockers
$1110(97.6 \%) \quad 1312(96.7 \%)$

0.15

$1013(89.1 \%)$

$1207(88.9 \%)$

0.47

$97(8.5 \%)$

$104(7.7 \%) \quad 0.47$

$1133(99.6 \%)$

$1351(99.5 \%)$

$0.76 \dagger$

$343(30.2 \%)$

$434(32.0 \%)$

0.32

$753(66.2 \%)$

$720(53.1 \%)<0.0001$

$981(86.3 \%)$

$997(73.5 \%)<0.0001$

$306(26.9 \%)$

$448(33.0 \%) \quad 0.0009$

$247(21.7 \%)$

$294(21.7 \%)$

0.97

$329(28.9 \%)$

$366(27.0 \%)$

0.27

$151(13.3 \%)$

$108(8.0 \%)<0.0001$

$422(37.1 \%)$

$444(32.7 \%) \quad 0.02$

$381(33.5 \%)$

$496(36.6 \%) \quad 0.11$ 
Supplemental Table 2. Baseline Clinical Characteristics, Procedural Characteristics and

\section{Baseline Medications in Patients with Preserved LVEF (cont)}

Variables are mean $\pm \mathrm{SD}, \mathrm{n}(\%)$, or median (IQR).

$*$ Wilcoxon $\mathrm{p}$ value. $\dagger$ Fisher $\mathrm{p}$ value.

+ Values were missing for body weight $(\mathrm{kg})$ in 48 patients, 15 in beta group and 33 in no-beta group.

$\S$ Values were missing for onset-to-balloon time (hours) in 338 patients, 166 in beta group and 172 in no-beta group.

|| Values were missing for door-to-balloon time (hours) in 364 patients, 184 in beta group and 180 in no-beta group.

\# Exclude 176 patients without stent implantation, 73 in beta group and 103 in no-beta group.

ACE-I $=$ angiotensin converting enzyme inhibitor, $\mathrm{ARB}=$ angiotensin receptor blocker, $\mathrm{BMI}$

$=$ body mass index, $\mathrm{COPD}=$ chronic obstructive pulmonary disease, $\mathrm{CTO}=$ chronic total occlusion, DES = drug-eluting stent, eGFR = estimated glomerular filtration rate, H2-blocker $=$ histamine type 2 receptor blocker, $\mathrm{LAD}=$ left anterior descending coronary artery, $\mathrm{LMCA}=$ left main coronary artery, and LVEF = left ventricular ejection fraction. 
Supplemental Table 3. Baseline Clinical Characteristics, Procedural Characteristics and Baseline Medications in Patients with Low LVEF

$\begin{array}{ccc}\beta \text { group } & \text { No- } \beta \text { group } & p \\ N=228 & N=222 & \text { value }\end{array}$

\section{(A) Clinical characteristics}

Age (years)

Age $\geq 75$ years

Male

Body weight $(\mathrm{kg})$

BMI

$\mathrm{BMI}<25.0$

Onset-to-balloon time (hours)

Onset-to-balloon time $\leq 6$ hours

Door-to-balloon time (hours) $\S$

Anterior infarction

Hypertension

Diabetes mellitus
$67.0 \pm 12.4 \quad 70.5 \pm 11.9 \quad 0.002$

$71(31.1 \%) \quad 90(40.5 \%) \quad 0.03$

$179(78.5 \%) \quad 160(72.1 \%) \quad 0.11$

$60(52-69) \ddagger \quad 59(50-66) \ddagger \quad 0.07$

$22.9(20.7-25.1) \quad 22.9(20.5-24.5) \quad 0.38^{*}$

$170(74.6 \%) \quad 181(81.5 \%) \quad 0.07$

$4.2(2.7-7.0) \S \quad 5.1(1.3-10.1) \S \quad 0.002 *$

$136(68.0 \%) \S \quad 115(58.1 \%) \S \quad 0.04$

$1.6(1.0-2.4)\|\quad 1.6(1.0-2.3)\| \quad 0.59 *$

$152(66.7 \%) \quad 159(71.6 \%) \quad 0.25$

$192(84.2 \%) \quad 167(75.2 \%) \quad 0.01$

$83(36.4 \%) \quad 69(31.1 \%) \quad 0.23$ 
Supplemental Table 3. Baseline Clinical Characteristics, Procedural Characteristics and

Baseline Medications in Patients with Low LVEF (cont)

\begin{tabular}{|c|c|c|c|}
\hline on insulin therapy & $12(5.3 \%)$ & $11(5.0 \%)$ & 0.88 \\
\hline Current smoking & $94(41.3 \%)$ & $84(37.8 \%)$ & 0.46 \\
\hline Heart failure & $122(53.5 \%)$ & $113(50.9 \%)$ & 0.57 \\
\hline Shock at presentation & $65(28.5 \%)$ & $42(18.9 \%)$ & 0.01 \\
\hline Multivessel disease & $119(52.2 \%)$ & $117(52.7 \%)$ & 0.91 \\
\hline Mitral regurgitation grade $3 / 4$ & $14(6.1 \%)$ & $10(4.5 \%)$ & 0.43 \\
\hline $\operatorname{LVEF}(\%)$ & $35(30-38)$ & $36(30.8-39)$ & $0.07 *$ \\
\hline Prior myocardial infarction & $33(14.5 \%)$ & $34(15.3 \%)$ & 0.8 \\
\hline Prior stroke & $22(9.7 \%)$ & $32(14.4 \%)$ & 0.11 \\
\hline Peripheral vascular disease & $9(4.0 \%)$ & $10(4.5 \%)$ & 0.76 \\
\hline eGFR $<30 \mathrm{ml} / \mathrm{min}$, not on dialysis & $16(7.0 \%)$ & $12(5.4 \%)$ & 0.47 \\
\hline Dialysis & $6(2.6 \%)$ & $6(2.7 \%)$ & 0.96 \\
\hline Atrial fibrillation & $31(13.6 \%)$ & $24(10.8 \%)$ & 0.36 \\
\hline Anemia $(\mathrm{Hb}<11.0 \mathrm{~g} / \mathrm{dl})$ & $24(10.5 \%)$ & $28(12.6 \%)$ & 0.48 \\
\hline Platelet $<100 * 10^{9} / \mathrm{L}$ & $5(2.2 \%)$ & $8(3.6 \%)$ & 0.36 \\
\hline COPD & $3(1.3 \%)$ & $15(6.8 \%)$ & 0.003 \\
\hline
\end{tabular}


Supplemental Table 3. Baseline Clinical Characteristics, Procedural Characteristics and Baseline Medications in Patients with Low LVEF (cont)

Liver cirrhosis

Malignancy

\section{(B) Procedural characteristics}

DES use

Number of target lesions

Target of proximal LAD

Target of unprotected LMCA

Target of CTO

Target of bifurcation

Side-branch stenting

Total number of stents

Total stent length (mm)

Total stent $>28 \mathrm{~mm}$

Minimum stent size (mm)

Minimum stent size $<3.0 \mathrm{~mm}$
$7(3.1 \%)$

$4(1.8 \%)$

0.38

$19(8.3 \%)$

$22(9.9 \%) \quad 0.56$

$80(35.1 \%)$

$81(36.5 \%)$

0.75

$1(1-2)$

$1(1-2)$

$0.14^{*}$

$159(69.7 \%)$

$159(71.6 \%) \quad 0.66$

$11(4.8 \%)$

$8(3.6 \%)$

0.51

$8(3.5 \%)$

$10(4.5 \%) \quad 0.58$

$63(27.6 \%)$

$76(34.2 \%)$

0.12

$4(1.8 \%)$

$8(3.6 \%)$

0.21

$1(1-2) \#$

$1(1-2) \#$

$0.09 *$

$28(20-44) \# \quad 24(18-40.3) \# \quad 0.07 *$

$98(45.6 \%) \# \quad 80(38.8 \%) \# \quad 0.16$

$3(2.5-3.5) \# \quad 3(2.8-3.5) \# \quad 0.37 *$

$79(36.7 \%) \# \quad 55(26.7 \%) \# \quad 0.02$ 
Supplemental Table 3. Baseline Clinical Characteristics, Procedural Characteristics and

Baseline Medications in Patients with Low LVEF (cont)

\section{(C) Discharge Medication}

Antiplatelet therapy

Thienopyridine

$221(96.9 \%)$

$214(96.4 \%)$

0.75

Ticlopidine

$200(87.7 \%)$

$204(91.9 \%) \quad 0.04$

Clopidogrel

$21(9.2 \%)$

$10(4.5 \%)$

0.04

Aspirin

$226(99.1 \%)$

$221(99.6 \%)$

$1 \uparrow$

Cilostazol

$72(31.6 \%)$

$98(44.1 \%)$

0.005

Other medications

Statins

$133(58.3 \%)$

$97(43.7 \%)$

0.001

ACE-I/ARB

$185(81.1 \%)$

$163(73.4 \%)$

0.05

Nitrates

$59(25.9 \%)$

$75(33.8 \%)$

0.06

Calcium channel blockers

$44(19.3 \%)$

$44(19.8 \%)$

0.88

Nicorandil

$57(25.0 \%)$

$54(24.3 \%)$

0.86

Warfarin

$63(27.6 \%)$

$43(19.4 \%)$

0.03

Proton pump inhibitors

$98(43.0 \%)$

$80(36.0 \%)$

0.13

H2-blockers

$65(28.5 \%)$

$80(36.0 \%)$

0.08 
Supplemental Table 3. Baseline Clinical Characteristics, Procedural Characteristics and

\section{Baseline Medications in Patients with Low LVEF (cont)}

Variables are mean $\pm \mathrm{SD}, \mathrm{n}(\%)$, or median (IQR).

$*$ Wilcoxon $\mathrm{p}$ value. $\dagger$ Fisher $\mathrm{p}$ value.

\$ Values were missing for body weight (kg) in 21 patients, 5 in beta group and 16 in no-beta group.

$\S$ Values were missing for onset-to-balloon time (hours) in 52 patients, 28 in beta group and 24 in no-beta group.

|| Values were missing for door-to-balloon time (hours) in 64 patients, 37 in beta group and 27 in no-beta group.

\# Exclude 29 patients without stent implantation, 13 in beta group and 16 in no-beta group.

ACE-I $=$ angiotensin converting enzyme inhibitor, $\mathrm{ARB}=$ angiotensin receptor blocker, $\mathrm{BMI}$

$=$ body mass index, $\mathrm{COPD}=$ chronic obstructive pulmonary disease, $\mathrm{CTO}=$ chronic total occlusion, DES = drug-eluting stent, eGFR = estimated glomerular filtration rate, H2-blocker $=$ histamine type 2 receptor blocker, $\mathrm{LAD}=$ left anterior descending coronary artery, $\mathrm{LMCA}=$ left main coronary artery, and LVEF = left ventricular ejection fraction. 
Supplemental Table 4. Baseline Clinical Characteristics According to Doses of Carvedilol

$\begin{array}{ccc}\text { Carvedilol } & \text { Carvedilol } \\ \geq \mathbf{1 0} \text { mg per day } & <10 \mathrm{mg} \text { per day } & \mathbf{p} \\ \mathrm{N}=385 & \mathrm{~N}=1,071 & \text { value }\end{array}$

\section{Clinical characteristics}

\begin{tabular}{|c|c|c|c|}
\hline Age (years) & $63.8 \pm 11.8$ & $66.5 \pm 12.4$ & $<0.0001$ \\
\hline$*$ Age $\geq 75$ years & $82(21.3 \%)$ & $297(27.7 \%)$ & 0.01 \\
\hline *Male & $320(83.1 \%)$ & $814(76.0 \%)$ & 0.003 \\
\hline Body weight $(\mathrm{kg})$ & $64(57-72)$ & $62(53-70)$ & $<0.0001$ \\
\hline BMI & $24.2(22.0-26.6)$ & $23.4(21.3-25.5)$ & $<0.0001 \uparrow$ \\
\hline$* \mathrm{BMI}<25.0$ & $242(62.9 \%)$ & $760(71.0 \%)$ & 0.003 \\
\hline Onset-to-balloon time (hours) & $4.1(2.8-6.5)$ & $4.1(2.7-6.7)$ & $0.66 \dagger$ \\
\hline Onset-to-balloon time $\leq 6$ hours & $244(72.0 \%) \ddagger$ & $649(70.5 \%) \ddagger$ & 0.06 \\
\hline Door-to-balloon time (hours) & $1.1(0.8-1.6) \S$ & $1(0.8-1.5) \S$ & $0.06 \dagger$ \\
\hline *Anterior infarction & $196(50.9 \%)$ & $583(54.4 \%)$ & 0.23 \\
\hline *Hypertension & $347(90.1 \%)$ & $899(83.9 \%)$ & 0.003 \\
\hline Diabetes mellitus & $136(35.3 \%)$ & $311(29.0 \%)$ & 0.02 \\
\hline
\end{tabular}


Supplemental Table 4. Baseline Clinical Characteristics According to Doses of Carvedilol

(cont)

*on insulin therapy

$14(3.6 \%)$

$36(3.4 \%)$

0.8

*Current smoking

$169(43.9 \%)$

$464(43.3 \%)$

0.84

*Heart failure

$92(23.9 \%)$

$322(30.1 \%) \quad 0.02$

*Shock at presentation

$40(10.4 \%)$

$174(16.2 \%) \quad 0.005$

*Multivessel disease

$205(53.2 \%)$

$525(49.0 \%) \quad 0.15$

*Mitral regurgitation grade 3/4

$8(2.1 \%)$

$25(2.3 \%)$

0.77

$\operatorname{LVEF}(\%)$

$54(47-62) \|$

$52(43-62) \| \quad 0.001 \dagger$

LVEF $\leq 40 \%$

$37(11.4 \%) \|$

$169(18.3 \%) \| \quad 0.003$

*Prior myocardial infarction

$32(8.3 \%)$

$92(8.6 \%)$

0.86

*Prior stroke

$37(9.6 \%)$

$73(6.8 \%)$

0.07

*Peripheral vascular disease

$12(3.1 \%)$

$32(3.0 \%)$

0.89

*eGFR $<30 \mathrm{ml} / \mathrm{min}$, not on dialysis

$17(4.4 \%)$

$27(2.5 \%) \quad 0.06$

*Dialysis

$4(1.0 \%)$

$18(1.7 \%)$

0.37

*Atrial fibrillation

$36(9.4 \%)$

$107(10.0 \%)$

0.71

*Anemia $(\mathrm{Hb}<11.0 \mathrm{~g} / \mathrm{dl})$

$25(6.5 \%)$

$98(9.2 \%)$

0.1

$*$ Platelet $<100 * 10^{9} / \mathrm{L}$

$4(1.0 \%)$

$18(1.7 \%)$

0.37 


\section{Supplemental Table 4. Baseline Clinical Characteristics According to Doses of Carvedilol}

\section{(cont)}

*COPD

$2(0.5 \%)$

$26(2.4 \%)$

0.01

*Liver cirrhosis

$6(1.6 \%)$

$34(3.2 \%)$

0.09

*Malignancy

$22(5.7 \%)$

$84(7.8 \%)$

0.16

Variables are mean $\pm \mathrm{SD}, \mathrm{n}(\%)$, or median (IQR). $*$ Clinically relevant risk variables selected for

multivariable Cox proportional-hazards model for doses of carvedilol.

$\dagger$ Wilcoxon $\mathrm{p}$ value.

\$ Values were missing for onset-to-balloon time (hours) in 196 patients, 46 in high dose group and 150 in low dose group.

$\S$ Values were missing for door-to-balloon time (hours) in 220 patients, 51 in high dose group and 169 in low dose group.

|| Values were missing for LVEF in 207 patients, 59 in high dose group and 148 in low dose group.

$\mathrm{BMI}=$ body mass index, $\mathrm{COPD}=$ chronic obstructive pulmonary disease, and $\mathrm{eGFR}=$ estimated

glomerular filtration rate, and $\mathrm{LVEF}=$ left ventricular ejection fraction. 
Supplemental Table 5. Crude Event Rates and Adjusted Hazard Ratio Through 3 Years

\section{According to Doses of Carvedilol}

\begin{tabular}{|c|c|c|c|c|c|}
\hline & Carvedilol & Carvedilol & & & \\
\hline & $\geq 10 \mathrm{mg}$ & $<10 \mathrm{mg}$ & Log-rank & Adjusted & \\
\hline & per day & per day & $\mathbf{p}$ & HR & $\mathbf{p}$ \\
\hline & $\mathrm{N}=385$ & $\mathrm{~N}=\mathbf{1 , 0 7 1}$ & value & {$[95 \% \mathrm{CI}]$} & value \\
\hline & & & & 0.65 & \\
\hline Cardiac death/MI & $17(4.7 \%)$ & $85(8.9 \%)$ & 0.02 & [0.38-1.05] & 0.08 \\
\hline & & & & 0.82 & \\
\hline All-cause death & $15(4.6 \%)$ & $74(8.5 \%)$ & 0.05 & {$[0.48-1.38]$} & 0.48 \\
\hline & & & & 0.57 & \\
\hline Cardiac death & $6(1.8 \%)$ & $40(4.6 \%)$ & 0.02 & {$[0.23-1.24]$} & 0.16 \\
\hline & & & & 0.65 & \\
\hline MI & $12(3.3 \%)$ & $55(5.6 \%)$ & 0.13 & {$[0.34-1.14]$} & 0.13 \\
\hline & & & & 1.10 & \\
\hline Hospitalization for $\mathrm{HF}$ & $21(5.9 \%)$ & $71(7.5 \%)$ & 0.68 & {$[0.56-2.04]$} & 0.76 \\
\hline
\end{tabular}

Variables are $\mathrm{n}(\%)$. Incidences at 3 years were estimated by the Kaplan-Meier method.

$\mathrm{CI}=$ confidence interval, $\mathrm{HF}=$ heart failure, $\mathrm{HR}=$ hazard ratio, $\mathrm{LVEF}=$ left ventricular

ejection fraction, and MI = myocardial infarction . 
Supplemental Table 6. Baseline Clinical Characteristics in Propensity Score Matched

\section{Population}

$\begin{array}{lll}\beta \text { group } & \text { No- } \beta \text { group } & p \\ N=1,614 & N=1,614 & \text { value }\end{array}$

Age $\geq 75$ years

$416(25.8 \%)$

$392(24.3 \%) \quad 0.32$

Male

$1,255(77.8 \%)$

$1,243(77.0 \%) \quad 0.61$

$\mathrm{BMI}<25.0$

$1,103(68.3 \%)$

$1,093(67.7 \%)$

Anterior infarction

$850(52.7 \%)$

$847(52.5 \%) \quad 0.91$

Hypertension

$1,386(85.9 \%)$

$1,388(86.0 \%) \quad 0.91$

DM on insulin therapy

$58(3.6 \%)$

$60(3.7 \%)$

0.2

Heart failure

$452(28.0 \%)$

$398(24.7 \%) \quad 0.03$

Shock at presentation

$234(14.5 \%)$

$187(11.6 \%) \quad 0.01$

Multivessel disease

$814(50.4 \%)$

$856(53.0 \%) \quad 0.13$

Prior myocardial infarction

$140(8.7 \%)$

$141(8.7 \%)$

0.95

Prior stroke

$121(7.5 \%)$

$135(8.4 \%)$

0.36

Peripheral vascular disease

$45(2.8 \%)$

$33(2.0 \%)$

0.16

Dialysis

$24(1.5 \%)$

$28(1.7 \%)$

0.57 
Supplemental Table 6. Baseline Clinical Characteristics in Propensity Score Matched

\section{Population (cont)}

Atrial fibrillation

$163(10.1 \%)$

$183(11.3 \%) \quad 0.25$

COPD

$31(1.9 \%)$

$21(1.3 \%)$

0.16

Liver cirrhosis

$43(2.7 \%)$

$41(2.5 \%) \quad 0.82$

Malignancy

$117(7.3 \%)$

$119(7.4 \%) \quad 0.89$

Target of proximal LAD

$947(58.7 \%)$

$966(59.9 \%) \quad 0.49$

Target of unprotected LMCA

$42(2.6 \%)$

$30(1.9 \%)$

0.15

Statins

$1,034(64.1 \%)$

$1,006(62.3 \%)$

0.3

ACE-I/ARB

$1,342(83.2 \%)$

$1,243(83.2 \%) \quad 0.96$

Nitrates

$421(26.1 \%)$

$405(25.1 \%) \quad 0.51$

Calcium channel blockers

$333(20.6 \%)$

$335(20.8 \%) \quad 0.93$

Nicorandil

$488(30.2 \%)$

$513(31.8 \%)$

0.34

Variables are $\mathrm{n}(\%)$. ACE-I $=$ angiotensin converting enzyme inhibitor, $\mathrm{ARB}=$ angiotensin receptor

blocker, $\mathrm{BMI}=$ body mass index, $\mathrm{COPD}=$ chronic obstructive pulmonary disease, $\mathrm{DM}=$ diabetes

mellitus, $\mathrm{LAD}=$ left anterior descending coronary artery, and LMCA = left main coronary artery. 
Supplemental Table 7. Event Rates Through 3 Years in Propensity Score Matched Population

\begin{tabular}{lccl}
\hline & $\boldsymbol{\beta}$ group & No- $\boldsymbol{\beta}$ group & $\mathbf{p}$ \\
& $\mathbf{N}=\mathbf{1 , 6 1 4}$ & $\mathbf{N = 1 , 6 1 4}$ & value \\
\hline Cardiac death/MI & $110(7.6 \%)$ & $92(6.1 \%)$ & 0.2 \\
All-cause death & $99(7.5 \%)$ & $117(8.1 \%)$ & 0.23 \\
Cardiac death & $50(3.7 \%)$ & $43(2.9 \%)$ & 0.46 \\
MI & $73(4.9 \%)$ & $59(3.9 \%)$ & 0.22 \\
Hospitalization for HF & $104(7.2 \%)$ & $53(3.9 \%)$ & $<0.0001$ \\
\hline
\end{tabular}

Incidences at 3 years were estimated by the Kaplan-Meier method.

$\mathrm{HF}=$ heart failure and $\mathrm{MI}=$ myocardial infarction. 